\title{
Dental and Periodontal Diseases Among United Nations Personnel in Mission: A Fifteen Months Experience of Rwanda Level 2 Hospital Bria in Central African Republic
}

\author{
Joël Bizimanasharale Bikoroti ${ }^{1}$, John Byimana ${ }^{1}$, Augustin Ndatinya ${ }^{2}$, Justin Bayisenga ${ }^{1}$, \\ John Muganda Rwibasira ${ }^{3}$, Alphonse Gasangwa ${ }^{2}$, Emmanuel Ntirenganya ${ }^{2}$, Sadock Rumenge ${ }^{2}$, \\ Venuste Nsengiyumva ${ }^{4}$, Eugène Tuyizere ${ }^{4}$ \\ ${ }^{1}$ Department of Surgery, Rwanda Level 2 Hospital, MINUSCA, Bria, Central African Republic \\ ${ }^{2}$ Department of Outpatient, Rwanda Level 2 Hospital, MINUSCA, Bria, Central African Republic \\ ${ }^{3}$ Department of Gynecology and Obstetrics, Rwanda Level 2 Hospital, MINUSCA, Bria, Central African Republic \\ ${ }^{4}$ Department of Dental, Rwanda Level 2 Hospital, MINUSCA, Bria, Central African Republic
}

Email address:

drbikorotijoel@gmail.com (J. B. Bikoroti),jbyimana@gmail.com (J. Byimana)

\section{To cite this article:}

Joël Bizimanasharale Bikoroti, John Byimana, Augustin Ndatinya, Justin Bayisenga, John Muganda Rwibasira, Alphonse Gasangwa, Emmanuel Ntirenganya, Sadock Rumenge, Venuste Nsengiyumva, Eugène Tuyizere. Dental and Periodontal Diseases Among United Nations Personnel in Mission: A Fifteen Months Experience of Rwanda Level 2 Hospital Bria in Central African Republic. International Journal of Dental Medicine. Vol. 3, No. 2, 2017, pp. 4-10. doi: 10.11648/j.ijdm.20170302.11

Received: June 30, 2017; Accepted: July 26, 2017; Published: August 30, 2017

\begin{abstract}
Oral diseases and orodental trauma are major public health problems worldwide and poor oral health has a profound effect on general health and quality of life. This retrospective study was conducted on dental visits at Rwandan Level 2 hospital Bria in Central African Republic from August 2015 to November 2016. Dental and periodontal diseases have been documented; demographic and analytical data were reviewed and analyzed. A total of 540 dental visits aged from 22 to 59 years; mean age of $37.57 \pm 8.15$ years. Male sex ratio of 9.6: 1 . Dental caries, gingivitis and periodontitis were more prevalent with $33.13 \%, 16.98 \%$ and $13.87 \%$ respectively. Scaling and root planning, permanent filling and extractions were the most treatment in $34 \%, 32.4 \%$ and $19.92 \%$ respectively. The teeth $16,26,36$ and 46 were found to be more diseased with $23 \%$, $25.52 \%, 30.17 \%$ and $27.15 \%$ respectively. Gingivitis and periodontitis showed a protection association with age of less than 37.57 years $\mathrm{p}=0.013, \mathrm{OR}=0.55,95 \% \mathrm{CI}(0.34-0.88)$ and $\mathrm{p}<0.001, \mathrm{OR}=0.38,95 \% \mathrm{CI}(0.22-0.64)$ respectively. Dental caries, Operculitis, fractured crown and teeth extractions showed strong statistical significance and risks with particular teeth. Dental and periodontal diseases are prevalent at Rwanda Level 2 hospital Bria. The different diseases and management have been documented. As per our hypothesis, dental caries were found to be the most common disease in this population. Particular statistical association of some diseased teeth has been shown.
\end{abstract}

Keywords: Dental, Periodontal, Disease, Rwanda Level 2 Hospital

\section{Introduction}

Chronic diseases and injuries are the leading health problems in all but a few parts of the world. Oral diseases qualify as major public health problems owing to their high prevalence and incidence in all regions of the world, as for all diseases, the greatest burden of oral diseases is on disadvantaged and socially marginalized populations $[1,2]$. The quality of life of workers is an issue that deserves attention, since the promotion of welfare benefits, such as medical and dental care to employees, are extremely efficient means and can be used by businesses in order to improve inter business competitiveness, in a globalized world [3].

The Security Council established the United Nations Multidimensional Integrated Stabilization Mission in the Central African Republic (MINUSCA) by its resolution 2149 (2104) on 10 April 2014 [4]. Rwanda Level 2 hospital is the 
UN hospital, which serves UN personnel based in Eastern headquarter. It is staffed with surgeons, anesthetists, gynecologist, internist physician, general practitioners, nurses and dental therapeutists.
The objective was to determine the burden of oral diseases in the zone covered by Rwanda Level 2 hospital Bria in Central African Republic.

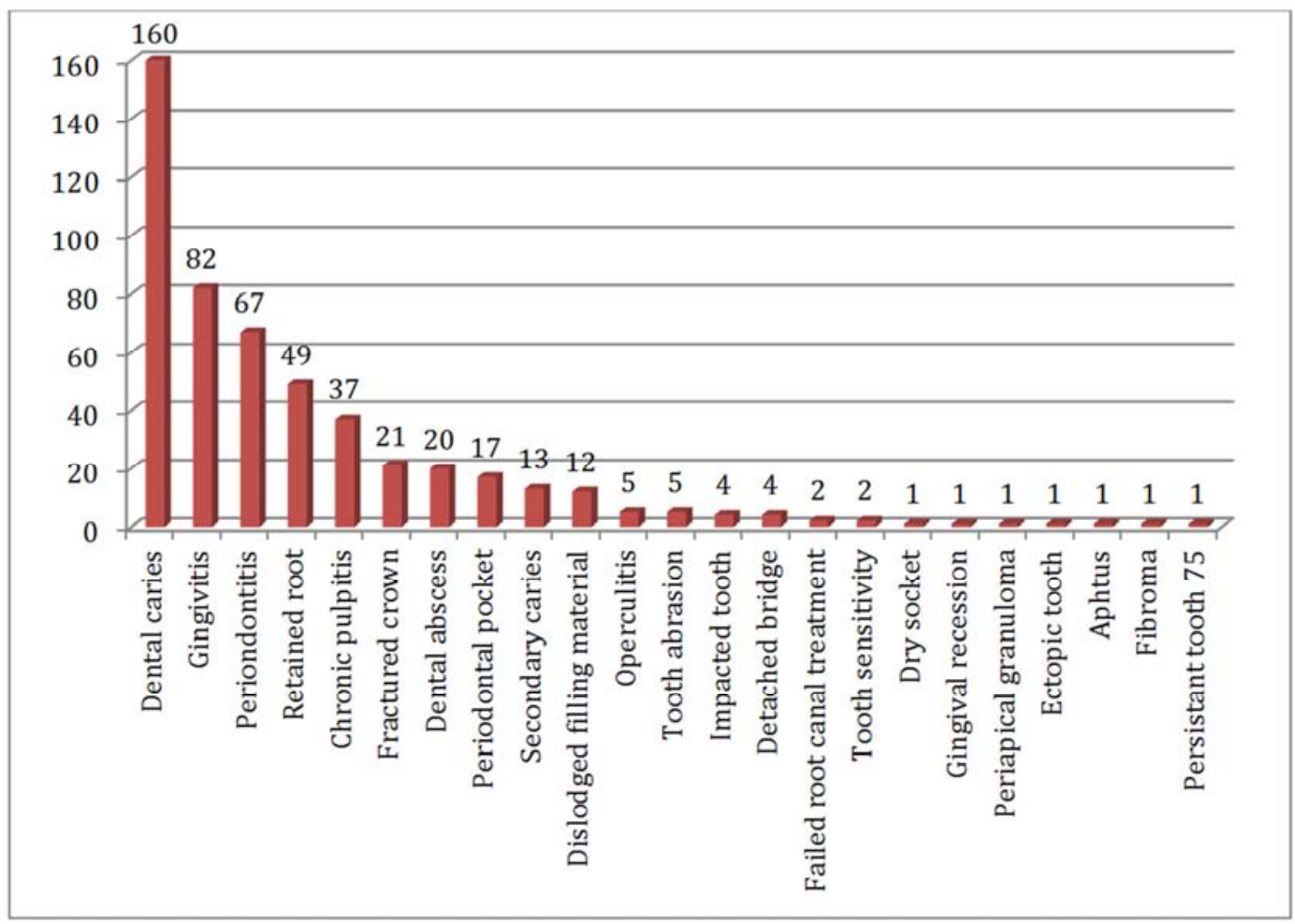

Figure 1. Dental and periodontal diagnoses.

\section{Materials and Methods}

This was a retrospective descriptive of data and records of patients who visited dental unit at UN Rwanda Level 2 hospital over a fifteen months period from August 2015 to November 2016. Were included all completed files for patients who consulted for dental and periodontal diseases. Proposal was submitted and approved by Rwanda Level 2 hospital ethical committee. Data were entered in the computer programme Statistical Package for the Social Sciences (SPSS) software version 16.0 and analyzed both with the aid of the computer programme SPSS and Microsoft Excel.

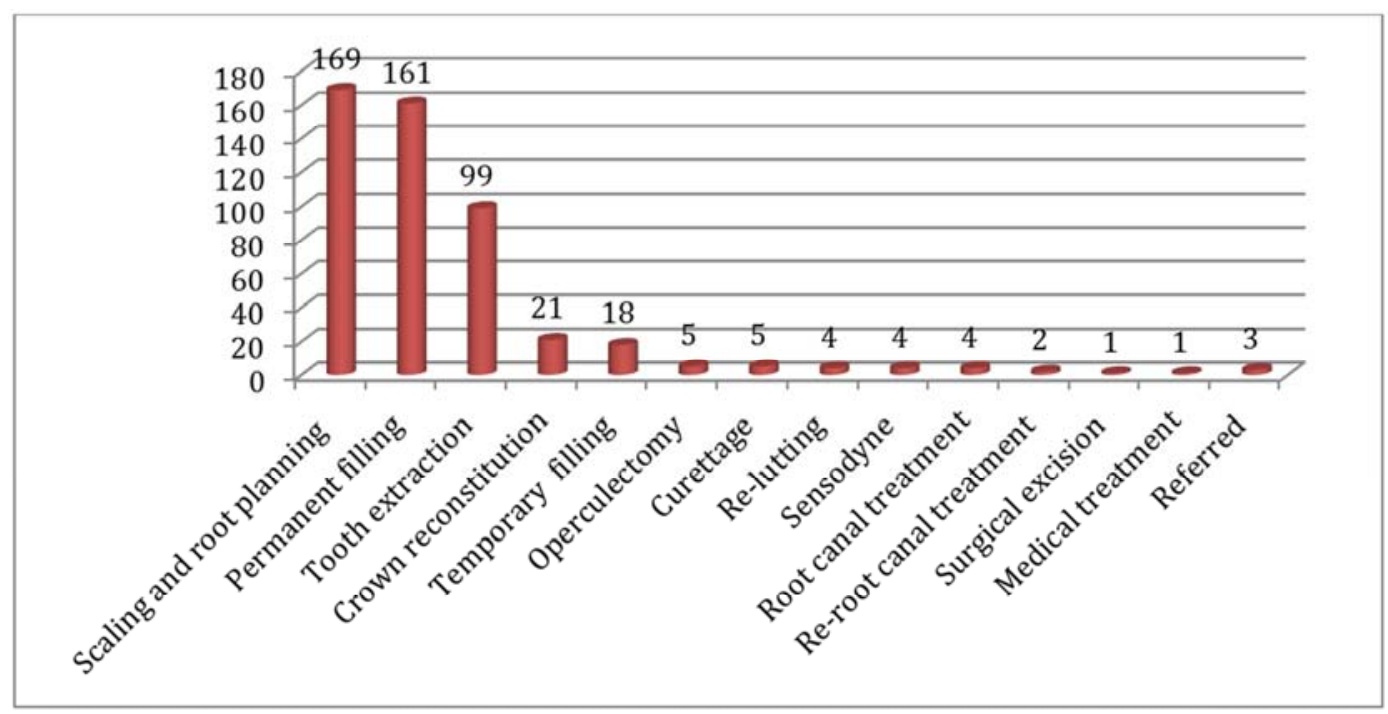

Figure 2. Management received. 
Descriptive statistics were used for frequencies, mean and analytical statistics were used for cross tabulations, 95\% confidence intervals applied as necessary.

The statistical test Pearson's Chi-square was computed only for $2 \times 2$ tables with cells which had expected count more than 5 and those having expected count less than 5, Fisher's Exact Test was used and the limit of significance was established at the probability less to $0.05(\mathrm{P}<0.05)$.

\section{Results and Discussion}

\subsection{Results}

316 patients' files were reviewed and a total of 540 dental visits met our inclusion criteria with a prevalence rate of $17.97 \%$. Males were predominant with $90.56 \%$ (sex ratio of 9.6: 1). The mean age was $37.57 \pm 8.15$ years, median of 36 years and mode being 35 . Contingent elements presented $69.26 \%$ of visits.

507 dental and periodontal diagnoses have been reviewed and managed and 33 visits were for follow up only without new diagnosis or added treatment.

\subsubsection{Distribution According to Dental and Periodontal Diagnoses}

Dental caries took the lead with $31.56 \%$, gingivitis with $16.17 \%$, periodontitis $13.21 \%$, retained root (root caries) $9.66 \%$, chronic pulpitis $7.29 \%$, fractured crown $4.14 \%$ and dental abscess with $3.94 \%$.

\subsubsection{Distribution According to Management Received}

497 dental and periodontal diseases have been reviewed and managed and 10 visits had diagnosis and needed x-rays for confirmation and after went back to their respective level 1 for management.

As mentioned above in the figure 2, Scaling and root planning, permanent filling and tooth extraction were in $86.32 \%$ the principal treatments given; crown reconstitution represented $4.22 \%$, temporary filling was the only treatment received for $3.62 \%$ found in the files (patients did not come back, rotations induced, etc.), one patient received medical treatment (for aphtus).

\subsubsection{Distribution According to Dental and Periodontal Diseases}

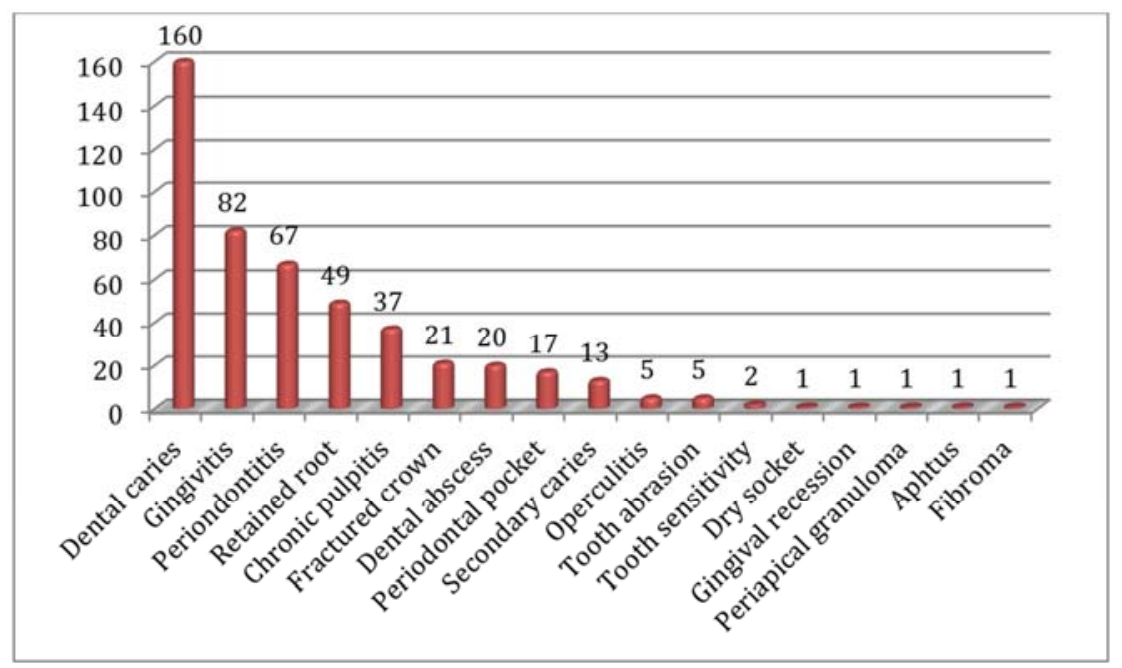

Figure 3. Dental and periodontal diseases.

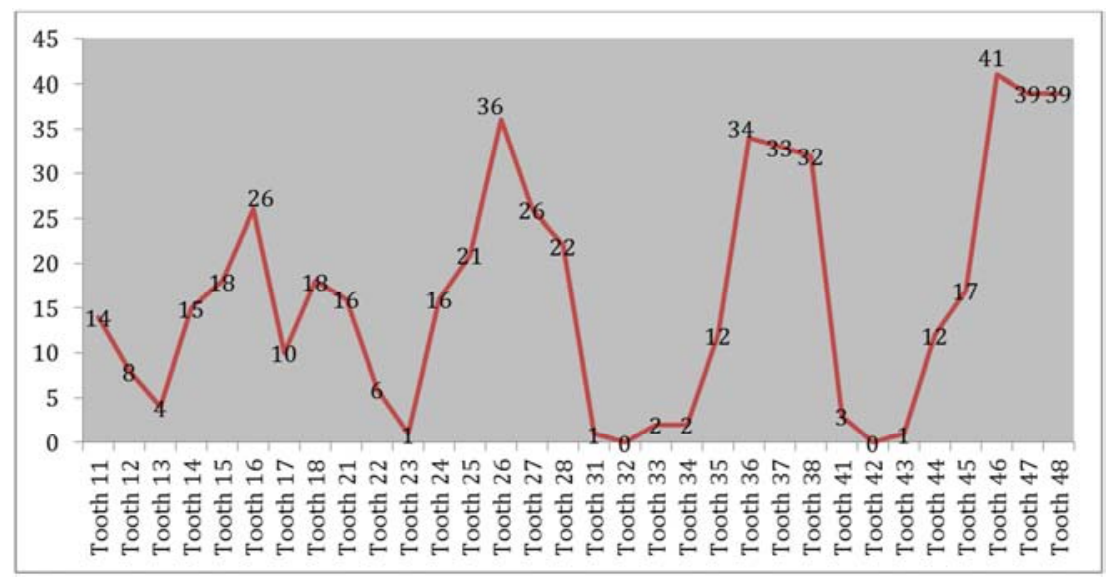

Figure 4. Frequency of diseased teeth review. 
As shown above, 483 diseases have treated. Dental caries took a leading prevalence of all dental and periodontal diseases visits with 160/483 (33.13\%) followed by gingivitis with $16.98 \%$, periodontitis with $13.87 \%$, teeth retained root at visit was $10.14 \%$, chronic pulpitis with $7.66 \%$, fractured crown with $4.35 \%$, dental abscess with $4.14 \%$.

Dental diseases were more frequent $(298=61.7 \%)$ than periodontal diseases $(185=38.3 \%)$.

\subsubsection{Distribution According to the Frequency of Diseased Teeth Review}

525 teeth were reviewed. The tooth 16 was more diseased in the first quadrant with $23 \%, 26$ being in the most in second quadrant with $25 \%, 36$ being the most in the third quadrant with $29.31 \%$ and 46 being the most in the fourth quadrant with $26.98 \%$.

Noted that the teeth 32 and 42 did not show any dental pathology during this cohort.

The teeth diseases distribution in quadrants (Q) were respectively: 21.52\% (Q1), 27.43\% (Q2), 22,1\%(Q3) and 28.95\% (Q4).

The teeth from Q1 and Q4 were affected (50.47\%) than Q2 and Q3 (49.53\%). And teeth from the maxillary jaw were less affected (49.95\%) than those from the mandibular jaw $(51.05 \%)$.

\subsubsection{Distribution According to Periodontal Diseases and Age}

Table 1. Periodontal diseases and AgePatients less to 37.57 years old were protected to develop periodontal diseases than olders, OR of 0.55 and 0.38 respectively.

\begin{tabular}{llllll}
\hline & & Age & (Years) & P value & OR (95\% CI) \\
\hline \multirow{4}{*}{ Gingivitis } & & $<37.57$ & $>37.57$ & & \\
& Yes & 35 & 47 & 0.013 & $0.55(0.34-0.88)$ \\
& No & 263 & 196 & & \\
& Yes & 23 & 44 & $<0.001$ & $0.38(0.22-0.64)$ \\
& No & 275 & 198 & & \\
\hline
\end{tabular}

\subsubsection{Caries Distribution According to the Most Probable Affected Teeth}

Table 2. Most probable affected teeth by Caries.

\begin{tabular}{|c|c|c|c|c|c|}
\hline & & \multicolumn{2}{|c|}{ Tooth 14} & $P$ value & OR $(95 \%$ CI $)$ \\
\hline & & Yes & No & \multirow{3}{*}{0.009} & \multirow{3}{*}{$3.71(1.3-10.61)$} \\
\hline & Yes & 9 & 151 & & \\
\hline & Non & 6 & 374 & & \\
\hline & & \multicolumn{2}{|c|}{ Tooth 15} & \multirow{4}{*}{0.014} & \multirow{4}{*}{$3.1(1.2-8)$} \\
\hline & & Yes & No & & \\
\hline & Yes & 10 & 150 & & \\
\hline & Non & 8 & 372 & & \\
\hline & & \multicolumn{2}{|c|}{ Tooth 21} & \multirow{5}{*}{0.018} & \multirow{5}{*}{$3.18(1.16-8.68)$} \\
\hline & & Yes & No & & \\
\hline & Yes & 9 & 151 & & \\
\hline & Non & 7 & 373 & & \\
\hline & & \multicolumn{2}{|c|}{ Tooth 22} & & \\
\hline \multirow{3}{*}{ Dental caries } & & Yes & No & \multirow{3}{*}{0.01} & \multirow{3}{*}{$\begin{array}{l}12.22(1.42- \\
105.5)\end{array}$} \\
\hline & Yes & 5 & 155 & & \\
\hline & Non & 1 & 379 & & \\
\hline
\end{tabular}

\begin{tabular}{|c|c|c|c|c|}
\hline & \multicolumn{2}{|l|}{ Tooth 14} & P value & OR $(95 \%$ CI) \\
\hline & \multicolumn{2}{|l|}{ Tooth 26} & \multirow{4}{*}{$<0.001$} & \multirow{4}{*}{$3.88(1.95-7.69)$} \\
\hline & Yes & No & & \\
\hline Yes & 22 & 138 & & \\
\hline Non & 15 & 365 & & \\
\hline & \multicolumn{2}{|c|}{ Tooth 44} & \multirow{4}{*}{$<0.001$} & \multirow{4}{*}{$12.6(2.73-58.19)$} \\
\hline & Yes & No & & \\
\hline Yes & 10 & 150 & & \\
\hline Non & 2 & 378 & & \\
\hline & \multicolumn{2}{|c|}{ Tooth 46} & \multirow{5}{*}{$<0.001$} & \multirow{5}{*}{$3(1.59-5.77)$} \\
\hline & Yes & No & & \\
\hline Yes & 22 & 138 & & \\
\hline Non & 19 & 361 & & \\
\hline & \multicolumn{2}{|c|}{ Tooth 47} & & \\
\hline & Yes & No & \multirow{3}{*}{0.001} & \multirow{3}{*}{$3(1.57-5.87)$} \\
\hline Yes & 21 & 139 & & \\
\hline Non & 18 & 362 & & \\
\hline
\end{tabular}

Dental caries were associated with tooth $14(\mathrm{p}=0.009$, $\mathrm{OR}=3.71 \quad(1.3-10.61)) ; 15 \quad(\mathrm{p}=0.014, \mathrm{OR}=3.1 \quad(1.2-8)) ; 21$ $(\mathrm{p}=0.018, \quad \mathrm{OR}=3.18 \quad(1.16-8.68)) ; 22 \quad(\mathrm{p}=0.01, \quad \mathrm{OR}=12.22$ $(1.42-105.5)) ; \quad 26 \quad(\mathrm{p}<0.001, \quad \mathrm{OR}=3.88 \quad(1.96-7.69)) ; 44$ $(\mathrm{p}<0.001, O R=12.6(2.73-58.19)) ; 46(\mathrm{p}<0.001, O R=3(1.59-$ 5.77) $)$ and $47(\mathrm{p}=0.001, \mathrm{OR}=3(1.57-5.87)$.

\subsubsection{Distribution According to Other Dental Diseases and Teeth}

Table 3. Other Caries diseases teeth.

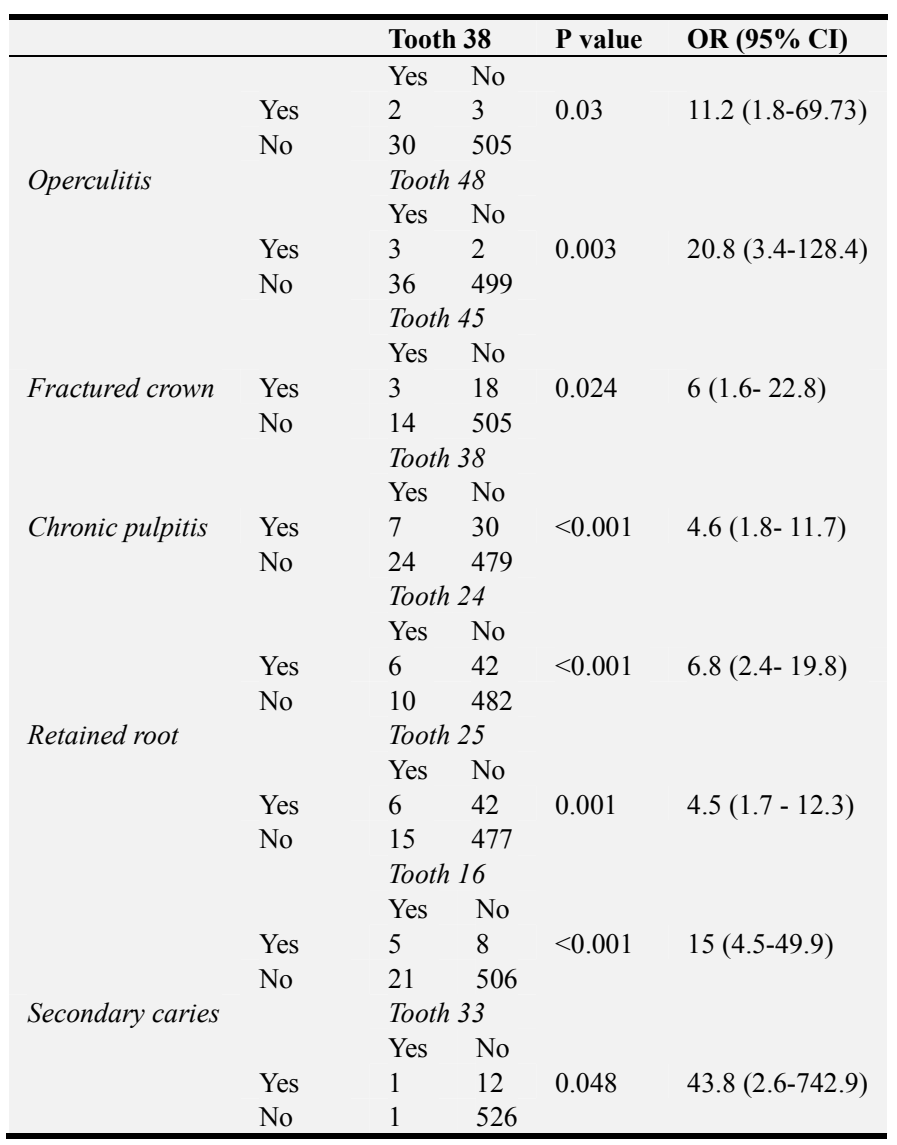

Operculitis showed a strong association with tooth 48 $\mathrm{p}=0.003, \mathrm{OR}=20.895 \%$ CI $(3.4-128.4)$ than $38 \mathrm{p}=0.03$, 
$\mathrm{OR}=11.295 \%$ CI (1.8-69.73).

Fractured crown showed an association with tooth 45 $\mathrm{p}=0.024, \mathrm{OR}=6,95 \% \mathrm{CI}(1.6-22.8)$. Retained root showed a strong association with teeth 24 and $25 \mathrm{p}<0.001, \mathrm{OR}=6.8$, $95 \%$ CI (2.4-19.8) and $\mathrm{p}=0.001, \mathrm{OR}=4.5,95 \% \mathrm{CI}(1.7-12.3)$ respectively.

The teeth 16 and 33 showed a significance association of developing secondary caries $(p=0.001$ and 0.048$)$ with relative risks of 15 and 43.8 times.

\subsubsection{Distribution According to the Tooth Risk for Extraction}

Table 4. Tooth risk for extraction.

\begin{tabular}{|c|c|c|c|c|c|}
\hline & & \multicolumn{2}{|c|}{ Tooth 18} & \multirow[t]{2}{*}{$P$ value } & \multirow[t]{2}{*}{ OR $(95 \%$ CI $)$} \\
\hline & & Yes & No & & \\
\hline & Yes & 7 & 92 & 0.022 & $2.9(1.12-7.8)$ \\
\hline & No & 11 & 430 & & \\
\hline & & \multicolumn{4}{|c|}{ Tooth 24} \\
\hline & & Yes & No & & \\
\hline & Yes & 7 & 92 & \multirow[t]{2}{*}{0.008} & \multirow[t]{2}{*}{$3.6(1.3-10)$} \\
\hline & No & 9 & 432 & & \\
\hline & & \multicolumn{2}{|c|}{ Tooth 36} & & \\
\hline & & Yes & No & & \\
\hline \multirow[t]{14}{*}{ Extraction } & Yes & 11 & 88 & 0.038 & $2.2(1-4.6)$ \\
\hline & No & 24 & 417 & & \\
\hline & & \multicolumn{2}{|c|}{ Tooth 37} & & \\
\hline & & Yes & No & \multirow{3}{*}{0.006} & \multirow{3}{*}{$2.7(1.3-5.8)$} \\
\hline & Yes & 12 & 87 & & \\
\hline & No & 21 & 420 & & \\
\hline & & \multicolumn{2}{|c|}{ Tooth 38} & \multirow{4}{*}{0.003} & \multirow{4}{*}{$3(1.4-6.5)$} \\
\hline & & Yes & No & & \\
\hline & Yes & 12 & 87 & & \\
\hline & No & 19 & 422 & & \\
\hline & & \multicolumn{2}{|c|}{ Tooth 48} & \multirow{4}{*}{0.009} & \\
\hline & & Yes & No & & \multirow{3}{*}{$2.5(1.2-5.1)$} \\
\hline & Yes & 13 & 86 & & \\
\hline & No & 25 & 416 & & \\
\hline
\end{tabular}

Tooth extraction showed a strong association with tooth 18 $(\mathrm{p}=0.022, \mathrm{OR}=2.9(1.12-7.8)) ; 24(\mathrm{p}=0.008, \mathrm{OR}=3.6(1.3-$ $10)) ; 36(\mathrm{p}=0.038, \mathrm{OR}=2.2(1-4.6)) ; 37(\mathrm{p}=0.006, \mathrm{OR}=2.7$ $(1.3-5.8)) ; 38(\mathrm{p}=0.003, \mathrm{OR}=3(1.4-7.6 .5))$ and $48(\mathrm{p}=0.009$, $\mathrm{OR}=2.5(1.2-5.1))$.

\subsection{Discussion}

Dental and periodontal diseases are prevalent at Rwanda Level 2 hospital Bria in Central African Republic with $17.97 \%$. These results are similar to those reported in [3], showed that among the most serious problem in the population of UNTAG peacekeepers, dental problems counted $13.1 \%$.

The prevalence could be reduced to $7.67 \%$ if a preemployment exams was done and exclude those with dental problems as found in the study done by Thaís Richter de Araújo et al. (2013), for preemployment exams, 10.24\% (720) of the candidates, from a total of 7,029, were excluded for dental reasons to reduce absenteeism in the workplace [5].

This study found a male sex ratio of 9.6: 1 where men represented 90.56\%. Barbara E et al. (2011-2012), Muhammad I et al. (2014-2015), Fabien Sauvet et al. (2006) found the same distribution $84 \%, 88.6 \%, \quad 97.39 \%$ respectively $[6,7,8]$.

From data of systematic review and oral-systemic research expands to include genetics and immunity in general, authors found the same distribution like our research where males' sex was prevalent: Shiau HJ et al. (2010) a systematic review of the literature and meta-analyses in sex differences in destructive periodontal disease estimates sex-related differences in the prevalence of periodontitis in men $37.4 \%$ versus 28.1\%, respectively [9]. Dan Sindelar, DMD (2015) found that men are at greater risk for developing destructive periodontal disease than women due to heightened innate immune response in men compared to women [10].

Patients' age was between 22 and 59 years old with a mean of $37.57 \pm 8.15$. These results are similar to results found by Muhammad I et al. (2016) in Darfur, where the age ranged from 20-60 years with a mean of $30.45 \pm 5.43$ years [7]. In the report from WHO (2012), severe periodontal (gum) disease, in general population, which may result in tooth loss, is found in 15-20\% of middle-aged (35-44 years) adults [11]. The study done by PD Garkoti et al. (2012), from a total of 8928 patients attended OPD, majority of patients were in 30-39 years of age group [12].

During the study, from 540 patients' visits, most common dental disease was dental caries in $33.13 \%$ followed by gingivitis in $16.98 \%$. These results are quite similar to those found by Smadi L et al. (2011-2013) in Jordan, with dental caries in $31.6 \%$ and gingivitis in $28.7 \%$ [13]. In [12] in India found dental caries in $54.54 \%$ while gingivitis represented $37.62 \%$. The study done by Raoul Bationo et al. in Burkina Faso (2015-2016) found dental caries at 47.1\% [14].

Dental caries took lead of dental diseases in UN personnel. The same results are found in general population where Bruce A. Dye et al. (2011-2012) found that, approximately $91 \%$ of U. S. adults aged 20-64 had dental caries in permanent teeth in 2011-2012 [15].

Regarding dental caries and quadrant distribution, this study found a difference where maxillary jaw had 51.9\% versus $49.1 \%$ for mandibular jaw. These results are comparable to those found by Mustafa Demirci et al. (2010) where caries distribution was higher in the maxillary jaw $(62.4 \%)$ than in the mandibular jaw (37.6\%) [16].

From the results, retained root caries represented $10.14 \%$ of all diagnosis. Other authors documented root caries among general and older adults: Hariyani $\mathrm{N}$ et al. (2017) found a prevalence of root caries of $25.3 \%$ in general adults of $15+$ years old on a sample of 5505. This difference is due to sample size that included in general population those younger from 15 and above years [17] while this study showed a range from 22 to 59 years old.

Like other authors, the prevalence rate of operculitis was $1.03 \%$, these results are similar to those found in [12] and in [14]. Their studies found rates of pericoronitis being $0.53 \%$ and $2 \%$ respectively. In this study, the tooth 48 was 10 times concerned by operculitis than tooth 38 which is similar to the result of Ilgu Lee: In 250 military enlisted soldiers visiting the dental clinic, dental caries and pericoronitis relating to a 
third molar are major frequent dental disease [18].

During analysis, one dry socket was found as complication occurring after tooth extraction in $0.2 \%$. These findings are similar the those of Hasan Momeni et al. (2011) who found that, over two-month period of the study, among of 4,779 patients, the incidence of dry socket was $0.6 \%$ [19].

Among the management options of dental and periodontal disease, this study found tooth extraction rate of $19.92 \%$ for combined dental and periodontal diseases. These results are comparable to those found by Jackson TH, Guez C et al. (2017) in the records of 2184 consecutive patients treated, where the overall extraction rate was below $25 \%$ in 2006 [20]. And those found by Ribeiro LS et al., where $8 \%$ of 225 patients had lost one tooth or more and $20 \%$ had lost eight teeth or more [21].

A protection risk of 0.38 to develop periodontitis once age less than 37.57 years (younger) was found. These findings are similar to those found by Gina Thornton-Evans et al. (2009-2010) who showed that periodontitis rate increased with age where adults' aged $\geq 65$ years increased periodontitis than those aged $\geq 30$ years in the United States [22].

\section{Conclusion}

Dental conditions constitute health visits during conflicts, deployments, and field training exercises. They are prevalent at Rwanda Level 2 hospital in Bria. The different diseases and management have been documented. As per our hypothesis, dental caries were found to be the most common disease in this population. Particular statistical association of some diseased teeth has been shown.

\section{References}

[1] Poul Erik Petersen, Denis Bourgeois, Hiroshi Ogawa, Saskia Estupinan-Day, Charlotte Ndiaye. The global burden of oral diseases and risks to oral health Bulletin of the World Health Organization 2005, 83: 661-669.

[2] Janet E. Roberts, Kristee E. E-H and Paula J. K. A descriptive analysis of dental conditions occurring during conflicts, deployments and field training exercises. 2000320 076, Report No 99-33, In Naval Health Research Center.

[3] Korzeniewski, Krzysztof. UNTAG (United Nations Assistance Group)- peacekeeping in Africa. The International Journal of Medicine, Jan-March, 2009 source volume: 2 source issue: 1 http://www.biomedsearch.com/article/UNTAG-UnitedNations-Transition- Assistance/203660810.html

[4] MINUSCA Mandate available, accessed on June 2017 http://www.un.org/en/peacekeeping/missions/minusca/mandat e.shtml

[5] Thaís Richter de Araújo, Dagmar de Paula Queluz. Preemployment exam analysis of a military company and its relation to oral health. Braz. J. Oral Sci. vol. 12 no. 4 Piracicaba Out. / Dez. 2013.

[6] Barbara E. W, Wiolette Sz-F, Rebecca J. Humphrey et al. Risk of Dental disease Non-Battle injuries and severity of dental disease in deployed U. S Army personnel. Military Medicine,
180, 5: 570, 2015.

[7] Muhammad Irfan A, Naveed Akhtar M, Ayesha Raj et al. Skin diseases among peacekeepers at United Nations and African Mission in Darfur. Journal of Pakistan Association of Dermatologists. 2016; 26 (1): 53-57.

[8] Capt Fabien Sauvet, LC Christian Lebeau, Capt Stephane Foucher, Maj Olivier Flusain, Co JC Jouanin, Brig gen JM Debonne. Operational Impact of health problems observed during a four-month military deployment in Ivory Coast. Military Medicine, 174, 9: 921, 2009.

[9] Shiau HJ, Reynolds MA. Sex differences in destructive periodontal disease: a systematic review. J Periodontol. 2010 Oct; 81 (10): 1379-89. doi: 10.1902/jop.2010.100044.

[10] Dan Sindelar, DMD. Periodontal Disease: Why Sex Matters, March 12, 2015 https://aaosh.org/periodontal-disease-whysex-matters.

[11] Oral health, Fact sheet $\mathrm{N}^{\circ} 318$, April 2012. Available at http://www.who.int/mediacentre/factsheets/fs318/en/

[12] PD Garkoti, C. M. S Rawati, Rajesh Kumar Singh, Vanita Rawa, Janki Bartwal, Neha Goyal. Pattern of dental diseases among patients attending Outpatient Department of dental: A Hospital cross-section study. Original article. Kumaun, India 2012. National Journal of medical research, print ISSN: 2249 4996 / eISSN: 22778810.

[13] Smadi L, Sumadi AA. Women's oral and dental health aspects in humanitarian missions and disasters: Jordanian experience. Am J Disaster Med. 2016 Winter; 11 (1): 43-8. doi: 10.5055/ajdm.2016.0223.

[14] Raoul Bationo, Wendpouiré P. L. Guiguimdé, Hamidou Ouédraogo, Blintim Somé. Dental emergencies in Burkina Faso Armed Forces. Dent Med Probl. 2017; 54 (1): 49-51.

[15] Bruce A. Dye, Gina Thornton-Evans, Xianfen Li, Timothy J. Iafolla. Dental Caries and Tooth Loss in Adults in the United States, 2011-2012 NCHS Data Brief No. 197, May 2015 https://www.cdc.gov/nchs/products/databriefs/db197.htm

[16] Mustafa Demirci, Safa Tuncer, and Ahmet Ayhan Yuceokur. Prevalence of Caries on Individual Tooth Surfaces and its distribution by Age and Gender in University Clinic Patients. Eur J Dent. 2010 Jul; 4 (3): 270-279.

[17] Hariyani N, Spencer AJ, Luzzi L, Do LG. Root caries experience among Australian adults. Gerodontology. 2017 May 10. doi: 10.1111/ger.12275.

[18] LTCOL Ilgu Lee. A Study on the Oral Health Awareness of Enlisted Soldiers, MAJ Jin sun Hong, Armed Forced Daejeon Hospital, Daejeon City, Republic of Korea. In World military Dental congress 2012 SDFDS annual meeting, Hong Kong 2012, August 26-29.

[19] Hasan Momeni, Shirin Shahnaseri and Zeinab Hamzeheil. Evaluation of relative distribution and risk factors in patients with dry socket referring to Yazd dental clinics. Dent Res J (Isfahan). 2011 Dec; 8 (Suppl 1): S84-S87.

[20] Jackson TH, Guez C, Lin FC, Proffit WR, Ko CC. Extraction frequencies at a university orthodontic clinic in the 21 st century: Demographic and diagnostic factors affecting the likelihood of extraction. Am J Orthod Dentofacial Orthop. 2017 Mar; 151 (3): 456-462. 
[21] Ribeiro LS, Dos Santos JN, Ramalho LM, Chaves S, Figueiredo AL, Cury PR. Risk indicators for tooth loss in Kiriri Adult Indians: a cross-sectional study. Int Dent J. 2015 Dec; 65 (6): 316-21. doi: 10.1111/idj.12187. Epub 2015 Oct 19.
[22] Gina Thornton-Evans, Paul Eke, Liang Wei, Astrid Palmer. Periodontitis Among Adults Aged $\geq 30$ Years - United States, 2009-2010. Supplements, November 22, 2013 / 62 (03); 129135. 